\title{
An analysis of the impact of Globalization and Economic Adjustment on Urban Governance
}

\author{
Eulanie Ouseley-Torrezao \\ Coordinator, Division of Social Sciences, University of Guyana Berbice Campus \\ Tain, Corentyne, Berbice
}

Tel: 1-592-337-2309Ｅ-mail: eulanie.ouseley@uog.edu.gy

Received: June 26, 2013 Accepted: August 10, 2013 DOI: 10.5296/jpag.v3i3.3883

\begin{abstract}
This paper discusses the concepts of globalization and urban governance and examines some of its effects on the governance of developing countries. It argues that globalization is three dimensional, having social, economic and political characteristics. It also highlighted that some policy measures such as decentralization, trade liberalization and currency devaluation have negatively impacted on the governance of cities.
\end{abstract}

Keywords: Globalization, Economic Adjustment, Governance, Decentralization, Trade Liberalization 


\section{Introduction}

It must first be understood that governance is not a term that is new. In fact, it has been around for civilizations although it is now being increasingly used in developmental theories. However, in my many readings, I have found that some theorists use the term governance synonymously with government and often neglect the role of civil society. To do this, poses many problems since governance is not only about governments and the way a government functions but it also involves other actors that do not make up the government. An understanding of what urban governance means can be deduced from a definition of governance itself and is best presented from the definitions that follow.

\subsection{What is Governance?}

As UN ESCAP (2007) puts it, governance is "the process of decision-making and the process by which decisions are implemented (or not implemented)". It is generally known that the decision-making process itself calls for the involvement of various actors. In terms of the governance of cities, the factor that determines who these actors are is the level of government (global, regional, national or local) and the type of government being considered. For example, actors can be from the public sector (governmental officials), or the civil society (NGOs, Community Based Organizations, mafia, interests groups, etc.) including the private sector (private investors) and engages all classes of society including the urban poor.

To enhanced this definition, the UNDP (1997: 2-3) defines governance as "the exercise of economic, political and administrative authority to manage a country's affairs at all levels. It compromises mechanisms, processes and institutions through which citizens and groups articulate their obligations and exercise legal rights; meet their obligations and mediate their differences." This definition is related not only to the state - when it speaks of "political and administrative authority' - but also civil society, including the private sector and their right to participation in effective decision-making.

Although the above UN definitions do present a good discussion, probably the best and most simplistic workable definition of governance is articulated in a 1995 study by McCarney, Halfani and Rodriguez (cited in McCarney, 1996:4) as "the relationship between civil society and the state, between rulers and the ruled, the government and the governed." This relationship is what separates the perception of governance from the perception of government and shows an interdependence of all members of a society. This interdependence should never be ignored in a government's pursuit of effective or 'good' governance.

Given that we understand the concept of governance, we can now envisage how globalization and economic adjustment can have a major impact on the governance of cities. It is very safe to say that the notion of globalization coupled with the pressure of economic adjustment policies has and will continue to pose numerous problems to the governance of cities.

\section{Globalization and Governance}

When I first heard of the term globalization, I understood it to be about the creation of a homogeneous 'global village' where communication, transportation, trading, culture, etc. will be incorporated, all for the greater good. Economists have made the term sound so appealing 
but neglected to visualize its impacts on urban governance. Although the concept is welcomed, it is not by choice. Governments have no alternative but to participate or be left in the backseat of development.

Now, when I speak of globalization, I still continue to acknowledge this 'global village' but have now extended my knowledge to understand the concept from its various aspects. For example, world traders can reach other nations in a matter of hours or communicate with other traders thousands of miles away within minutes via the telephone or internet - this is just part of the world of globalization.

\subsection{Dimensions of Globalization}

As Keohane and Nye (2000), (cited in Dreher, 2003:4) highlighted, globalization is three dimensional, that is, it is either:

○ Social - expressed as the spread of ideas, information, images, and people.

- Political - characterized by a diffusion of government policies and

- Economical - characterized as long distance flow of goods, capital and services as well as information and perceptions that accompany market exchanges,

Given these characteristics, we can see that globalization presents many threats to the governance of cities and indicate that state restructuring is a factor that is inevitable. While there are many success stories, globalization do have some disparities. I intend to focus on these disparities and their effect on urban governance from a social, political and economical perspective.

\subsubsection{Social Dimension}

Socially, Hirst (2005:14) mentioned that there are many forces in the city (resulting from globalization) that can produce an 'exurban, post-public and culturally heterogeneous future.' The UN Millennium Report supports this view through its statement that "globalization can bring on ... social dislocation." I conceive the societal aspect of this statement to be true since we exist in a plural society composed of varying cultures, ethnicities, religions, and classes. Due to this, 'cultural pluralism', used by Hirst (2005,) can threaten the governance of cities. How so? Because different groups tend to maintain their unique cultural identities and, as such, conflict can exist when one group perceive their culture to be more dominant. Other groups may also reject diversity. For example the case of the Muslims in London and their determination to clothed in their cultural attire when the 'national' culture is not willing to permit it. With individualisation and choice being considered in any democratic society, cities will be forced to adjust their cultural policies in keeping with the aspect of governance with the focus being on maintaining the 'relationship' among the actors.

Another factor to consider in this 'social globalization' is what Hirst (2005) termed 'exurbanisation'. This, I conceive to be a merger of the city and the countryside whereby people move from the city to the rural areas but has maintained an urban lifestyle. This is prevalent in Latin America and the Caribbean since increased tourism, through globalization, has resulted in the construction of resorts and other commercial facilities in rural areas. The 
Dominican Republic case is that land that was once segregated for agricultural and other rural purposes is now being converted into industrial and residential use with land and house values on the rise which in turn has led to what is referred to as 'gentrification' (Cabannes, 2006). The impact of this is that there is widespread conflict in the area with massive eviction and isolation of the locality. Of course, this aspect puts added pressure on urban and local governance and can best be described as what Ed Soja called "city-full non-cityness" (cited in Hirst, 2005: 18).

\subsubsection{Political Dimension}

From a political perspective, many cities around the globe are now bombarded with international embassies and ambassadors. In addition, they are members of international organizations such as the World Bank, United Nations, etc. This provides many opportunities for countries in the developing world in terms of trade and commerce and financial aid but the result is that there is major restructuring to its governance.

For example, countries such as Guyana in South America were forced to redress their policies when it ratified the CEDAW Legislation (Constitution on the Elimination of all forms of Discrimination Against Women). The result was positive in that Women's Bureau and other female-sensitive institutions were set up to deal with issues such as domestic violence, sexual harassment, etc. and provision was made for approximately $30 \%$ female representation in decision-making bodies at the political level.

From a negative viewpoint, political globalization also threatens urban governance. For example, many cases have been reported whereby the diplomatic immunity offered to foreign ambassadors and their immediate families have been taken advantage of for their personal gain.

In addition, countries have diffused their policies in an attempt to attract capital which is evident in the deregulation, privatization, and other conditionalities imposed by bi-lateral and multi-lateral lending institutions (Waltz, 1999). Given this scenario, they can be sanctioned from deviating from these conditionalities. The result is that countries are now put in what Waltz (1999) termed as being a 'straitjacket' with no room for maneuver. The big question is: Are governments equipped enough to address the issues of governance that this has brought to the forefront? It does not only threaten governance but also the economic stability of countries. Criminals and other groups now find it easier to traffic in drugs, arms, and even people, putting a further threat on urban governance since it is usually in cities that these activities take place.

To add to this, these institutions are now promoting good governance which I believe to be a very unrealistic concept. This involves functioning under the rule of law with governments that are transparent, accountable, efficient, and effective and encourage participation, all of which should be consensus-oriented. Now you may ask why I believe this to be unrealistic. Simply put, as I mentioned before, we exist in plural society, and as such, we will never share the same beliefs and values and thus will never achieve full consensus. Another issue to consider is who or what determines who should have access to participation and other public services, particularly if it is a society that is structured by class as is the case of India. 


\section{Economic Adjustment and Governance}

'Structural adjustment' or 'economic adjustment' is a concept that emerged in developing countries in the early eighties. Over the years, my readings have taught me that 'adjustment' involves a set of policies that were imposed by the Bretton Wood Institutions (IMF and the World Bank) as a condition for the receipt of loans.

Although there is a general belief that structural adjustment fosters democratization, economic growth, and development, the emergence of these policies created new pressures since cities were forced to reform and adopt a neoliberal perspective of governance. The elements imposed generally included the retreat of the state, public sector reform: decentralization, privatization of state owned industries, currency devaluation, and trade liberalization. As McCarney (1996) opined, this reform (decentralization) is one of the most significant factors that affect urban governance. Many other groups also support McCarney's view including NGOs, grassroot organizations, economists and social scientists. They believe that Structural Adjustment Policies increases the gap between the rich and poor countries and promotes population dislocation and displacement. While the case is very debatable, I intend to focus on certain aspects of structural adjustment and their effect on urban governance.

\section{The Impact of Some Policy Measures on Urban Governance}

\subsection{Decentralization}

The decentralization aspect, while it can be positive, it does present many problems of governance. It is important to note that, according to McCarney (1996); a decentralized system does not mean an effective system and will not necessarily lead to democratization at the local level. First, while the authority to deliver services is often delegated from the central to the local level, it is not always accompanied by the financial resources needed to carry out this mandate.

In Guyana, for example, local governments receive subventions from central government to deliver services but it is not always adequate for the local system to function effectively. It does not help that local government is not entirely capable of raising revenues with its outdated tax collection system and inefficient and untrained staff. This 'relationship between civil society and the state' that McCarney (1996) mentioned is threatened since there is vast marginalization in terms of who gets access to the services and this often leads to racial tension.

Consequently, local government has been faced with a significant increase in pressure from civil society organizations that represent various interests. "These groups, together with other, more formal, private sector organizations, constitute an urban civil society which has increased its political and economic space and created a power block in the urban centers" (McCarney, 1996:12). What McCarney means is that these groups have bonded together for self subsistence to provide services that are beyond the reach of government or which local governments have chosen not to, or neglected to provide.

\subsection{Trade Liberalization}

Structural adjustment also calls for trade liberalization and/or the elimination of import 
controls. I strongly believe that this could negatively impact on the domestic market (owners of capital and labour) since, with unrestricted importation, there can be an influx of unnecessary goods. This, coupled with the devaluation policies, can result in imported goods being cheaper and more affordable. Consequently, there will be less demand for 'home grown' produce which can threaten the existence of local producers.

Further, currency devaluation was implemented with the intention of increasing the price of imports and reducing the price of exports. In terms of export prices, this may not be the case since in some countries; exports are already being sold at pre-determined prices. For example, in Guyana, the price of sugar in the world market is much higher than other competitors. This is due to the fact that the country is not fully industrialized and depends heavily on imported machinery and other capital equipment - whose costs have increased due to this policy. As such, in order to remain competitive, the sugar corporation is forced to 'cut back' which is usually in the area of labour costs resulting in social unrest as a result of frequent restrictive practices.

Additionally, removing price controls and subsidies, while it results in increased prices that benefit local producers, it also has a negative impact on the urban poor, particularly those in the informal sector. This, of course, is responsible for the rise of the informal sector and 'black market' operations.

\section{Conclusion}

Given the factors presented above, it can be seen that these so called 'developmental policies' have more benefited the countries in the west as they have gained more control over the economies of indebted countries. Rather than aid in poverty reduction and increasing the trade and production capacities of developing countries, the result is that there is few, if any economic growth, few loans are being serviced which results on added pressure on these developing countries to seek debt forgiveness as debt, inequalities, coupled with poverty has increased since implementation. The effect of this on the governance of poorer countries is devastating and in my opinion, supports the old adage - 'digging one hole to full another.'

\section{References}

Cabannes, Yves, (2006). Lecture - Development Planning Unit, University College London.

Dreher, Axel (2003), "Does globalization affect growth" [URL: http://129.3.20.41/eps/dev/papers/0210/0210004.pdf], (accessed 3 January 2007)

Hirst, P (2005), "Cities, Globalization and Governance", in P. Hirst, Space and Power: Politics, War and Architecture, Polity, London.

McCarney, P (1996), “Considerations in the Notion of 'Governance': New Directions for Cities in the Developing World", in P. McCarney (ed) Cities and Governance: New Directions in Latin America, Asia and Africa, Centre for Urban and Community Studies, Toronto.

United Nations Millennium Report, "Globalization and governance" [URL: http://www.un.orgmillenniumsgreportch1.pdf], (accessed 3 January 2007) 


\section{Macrothink}

UNDP (1997) “Governance for Sustainable Human Development” UNDP Policy Paper

UN ESCAP, “What is good governance?” [http://www.unescap.org/huset/gg/governance.htm], (accessed 3 January 2007).

Waltz, Kenneth (1999), “Globalization and Governance”, Columbia University

\section{Copyright Disclaimer}

Copyright reserved by the author.

This article is an open-access article distributed under the terms and conditions of the Creative Commons Attribution license (http://creativecommons.org/licenses/by/3.0/). 